\title{
Beyond the Pore Size Limitation of Nanoporous Graphene Monolayer Membrane for Water Desalination Assisted by External Electric Field
}

Haiqi Gao, ${ }^{\dagger}$ Qinghao Xu, ${ }^{\dagger}$ Jing Wang, ${ }^{\ddagger}$ Cai Ning, ${ }^{\S}$ Yuzhen Liu, ${ }^{\star}$ Yannan Xie, ${ }^{*}{ }^{\dagger}$ and Ruifeng $\mathrm{Lu}^{*}+$

'State Key Laboratory of Organic Electronics and Information Displays \& Institute of Advanced Materials (IAM), Nanjing University of Posts \& Telecommunications, 9 Wenyuan Road, Nanjing 210023, People's Republic of China.

Institute of Ultrafast Optical Physics, MIIT Key Laboratory of Semiconductor Microstructure and Quantum Sensing, Nanjing University of Science and Technology, Nanjing 210094, People's Republic of China ${ }^{\S}$ School of Physics, Southeast University, Nanjing 211189, People's Republic of China.

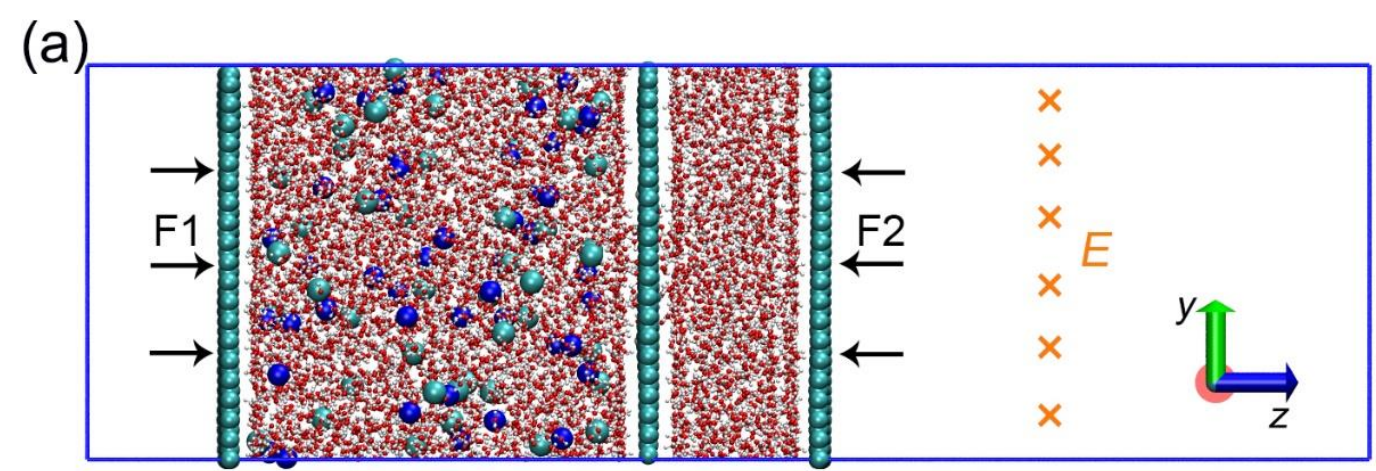

(b)

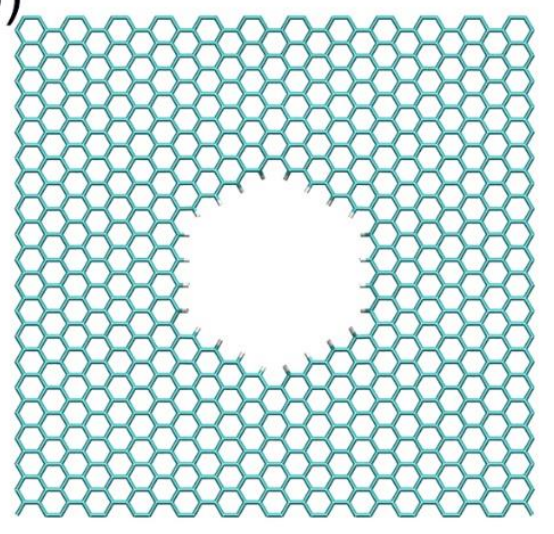

(c)

Figure S1. (a) Schematic diagram of the simulation box. (b) Top view of porous graphene with 2-nm diameter pore. (c) Top view of porous graphene with 1-nm diameter pore (slightly larger than the size of hydrated ion). 
Table S1. The bias voltage in the $x$ direction versus the applied electric field

\begin{tabular}{|c|c|}
\hline Bias voltage & Applied electric field \\
\hline 0 & 0 \\
\hline $0.51 \mathrm{~V}$ & $0.1 \mathrm{~V} / \mathrm{nm}$ \\
\hline $1.54 \mathrm{~V}$ & $0.3 \mathrm{~V} / \mathrm{nm}$ \\
\hline $2.56 \mathrm{~V}$ & $0.5 \mathrm{~V} / \mathrm{nm}$ \\
\hline $5.12 \mathrm{~V}$ & $1.0 \mathrm{~V} / \mathrm{nm}$ \\
\hline $6.14 \mathrm{~V}$ & $1.2 \mathrm{~V} / \mathrm{nm}$ \\
\hline $7.68 \mathrm{~V}$ & $1.5 \mathrm{~V} / \mathrm{nm}$ \\
\hline
\end{tabular}

Table S2. Simulation time under different pressure

\begin{tabular}{|c|c|}
\hline Applied pressure & Simulation time \\
\hline $10 \mathrm{MPa}$ & $50 \mathrm{~ns}$ \\
\hline $30 \mathrm{MPa}$ & $20 \mathrm{~ns}$ \\
\hline $50 \mathrm{MPa}$ & $12 \mathrm{~ns}$ \\
\hline $100 \mathrm{MPa}$ & $5 \mathrm{~ns}$ \\
\hline
\end{tabular}

Table S3. The charges and Lennard-Jones parameters.

\begin{tabular}{|c|c|c|c|c|}
\hline Atoms name & Atom type & $\varepsilon(\mathrm{kJ} / \mathrm{mol})$ & $\sigma(\mathbf{n m})$ & $q(e)$ \\
\hline $\mathbf{O}_{\mathbf{W}}$ & opls_116 & 0.65019 & 0.31655 & -0.82 \\
\hline $\mathbf{H}_{\mathrm{W} 1}$ & opls_117 & 0 & 0 & 0.41 \\
\hline Hw2 & opls_117 & 0 & 0 & 0.41 \\
\hline $\mathbf{C}$ & opls_147 & 0.2928 & 0.3550 & 0 \\
\hline $\mathbf{H}_{\mathbf{C}}$ & opls_146 & 0.1255 & 0.2420 & 0.115 \\
\hline $\mathbf{C}_{\mathbf{H}}$ & opls_145 & 0.2928 & 0.3550 & -0.115 \\
\hline Co & opls_147 & 0.2928 & 0.3550 & 0.265 \\
\hline $\mathbf{O}_{\mathbf{C}}$ & opls_023 & 0.71128 & 0.307 & -0.7 \\
\hline $\mathbf{H}_{\mathbf{O}}$ & opls_024 & 0 & 0 & 0.435 \\
\hline
\end{tabular}




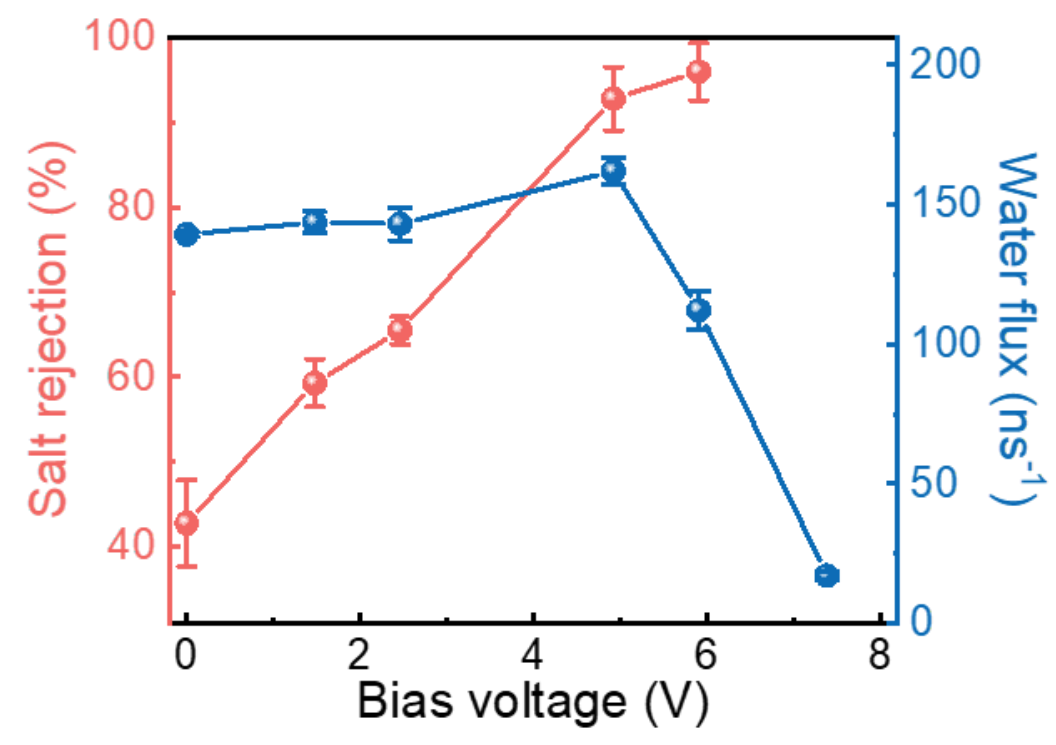

Figure S2. Water flux and salt rejection with respect to $V_{x}$ under pressures of $30 \mathrm{MPa}$ for OH-passivated pore.

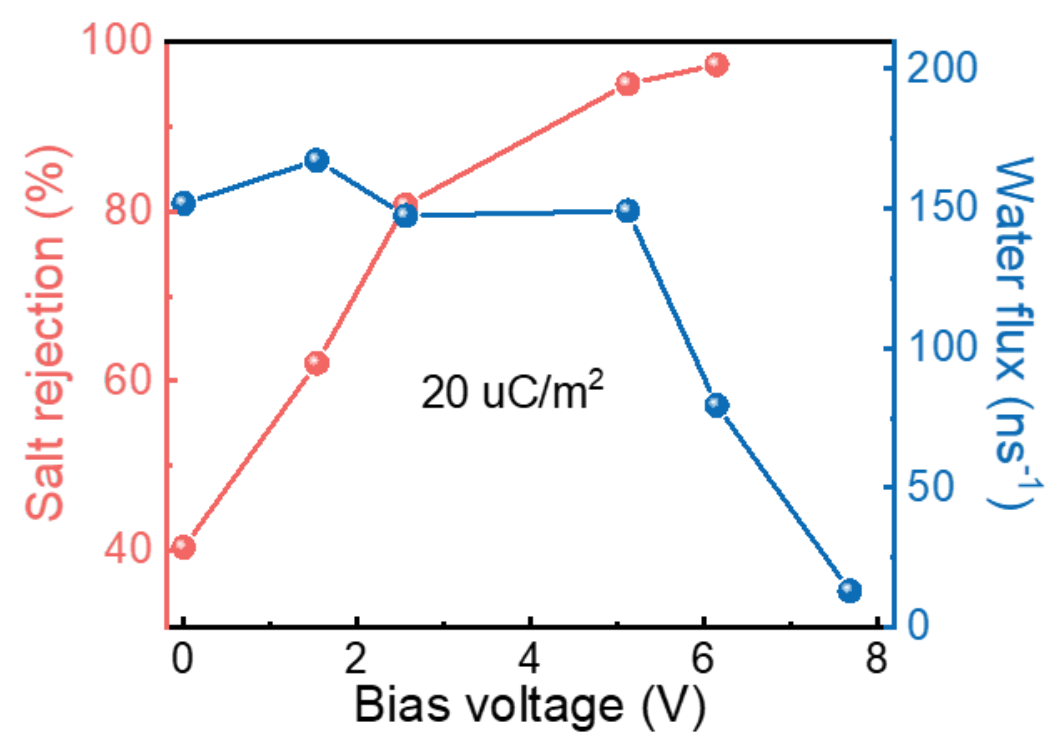

Figure S3. Water flux and salt rejection with respect to $V_{x}$ under pressures of $30 \mathrm{MPa}$ for the $\mathrm{H}$-passivated nanoporous membrane with surface charge density of $20 \mathrm{uC} / \mathrm{m}^{2}$. 
(b)
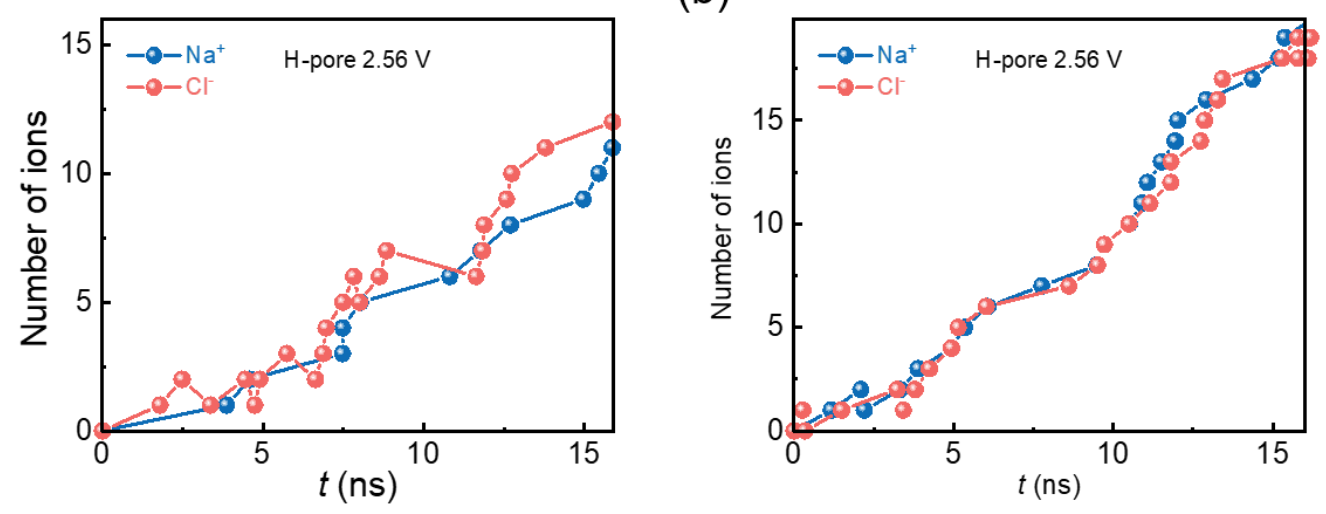

Figure S4. The number of $\mathrm{Na}^{+}$and $\mathrm{Cl}^{-}$passing through (a) - $\mathrm{H}$ and (b) -OH passivated nanoporous graphene membrane under the pressure of $30 \mathrm{MPa}$ and bias voltage of $2.56 \mathrm{~V}$ in $x$ direction.

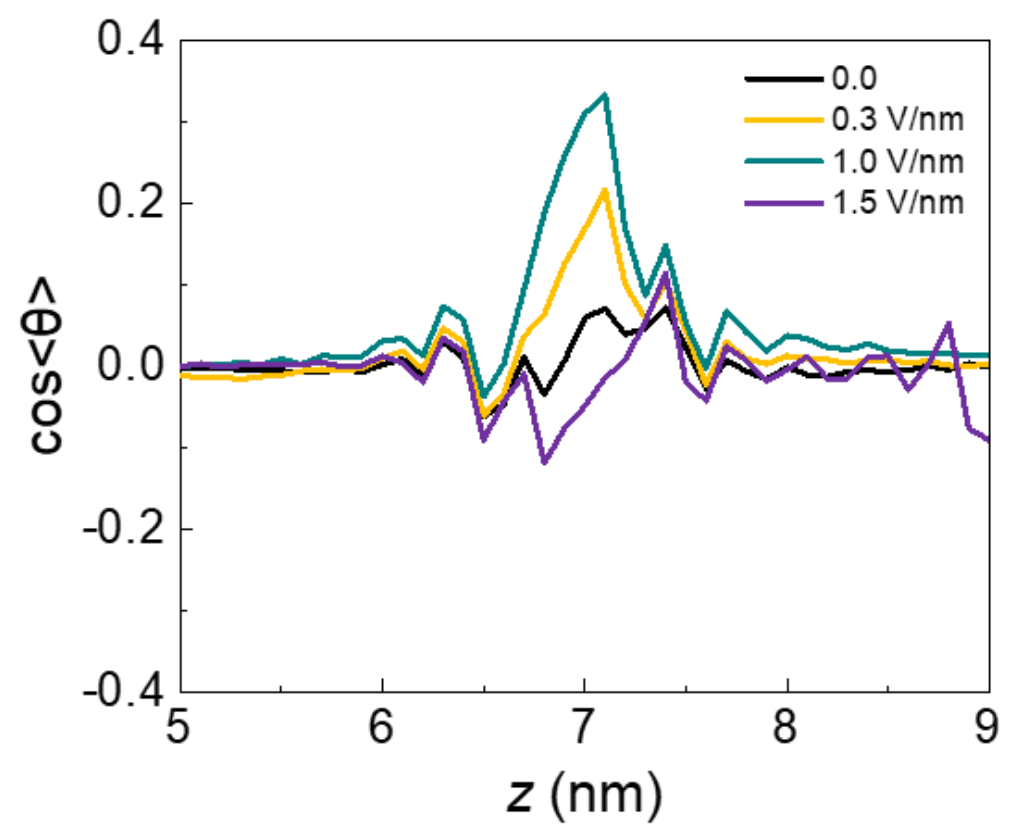

Figure S5. Average orientation of water molecule as a function of the simulation box length in $z$ direction under different vertical electric field. 


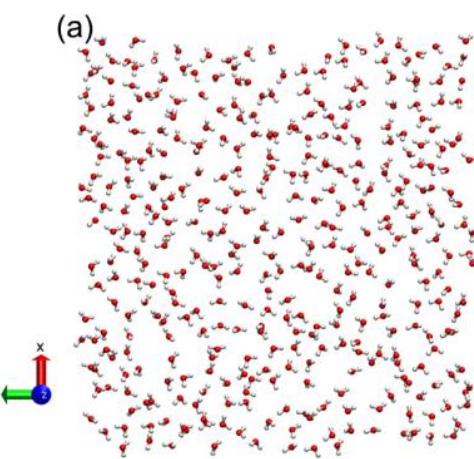

0.0 permeate (b).

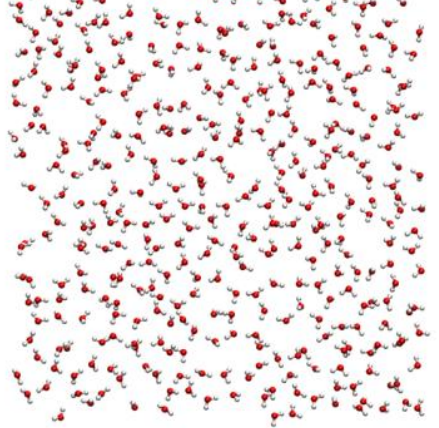

$1.5 \mathrm{~V} / \mathrm{nm}-\mathrm{z}$ permeate (c)

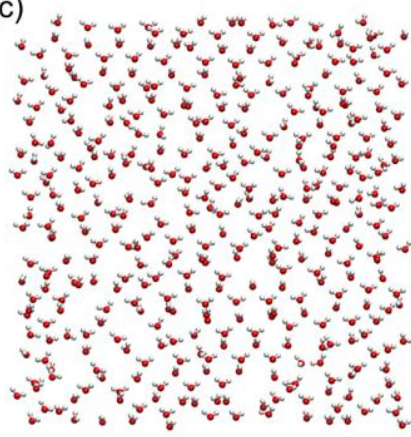

$1.5 \mathrm{~V} / \mathrm{nm}-\mathrm{x}$ permeate

Figure S6. Snapshot of water structure.

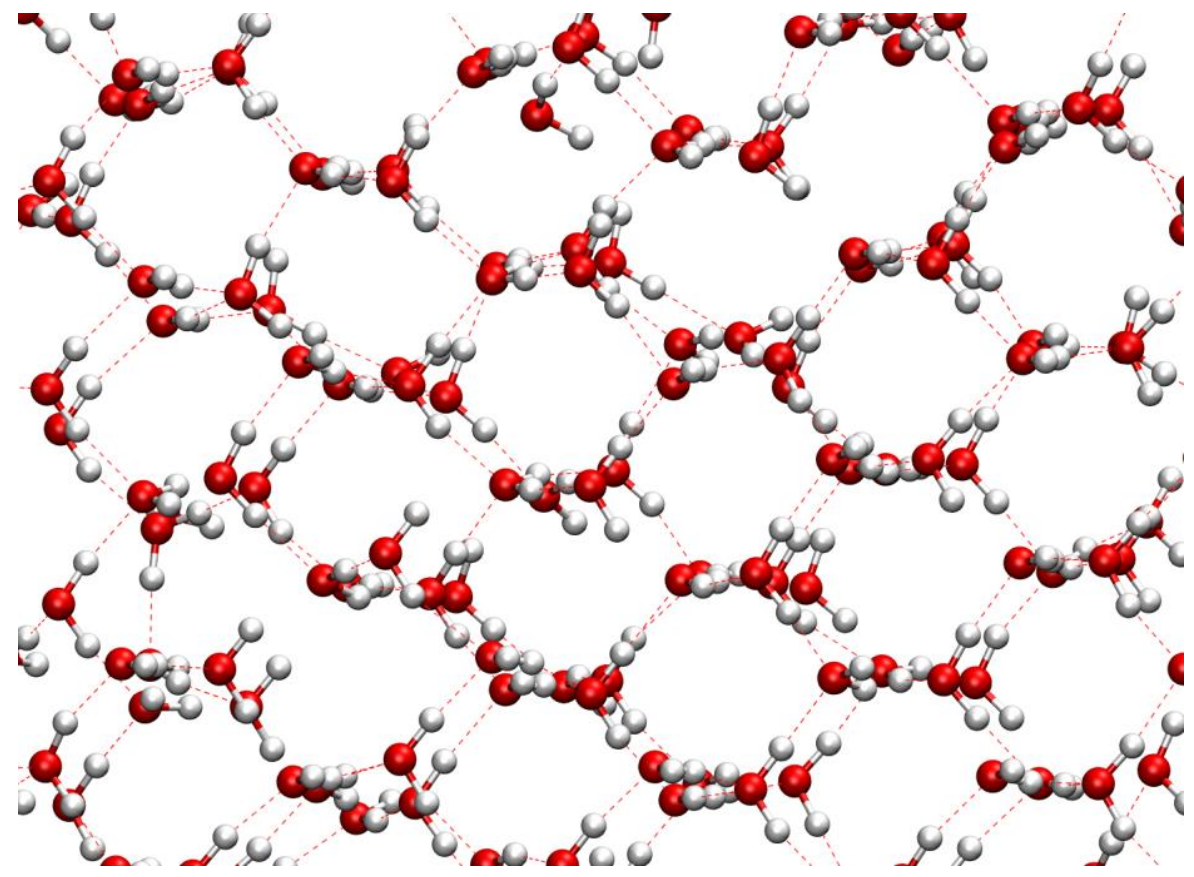

Figure S7. Snapshot of ice-like water structure in the pure water reservoir (permeate side) under the vertical bias voltage of $7.68 \mathrm{~V}$. 


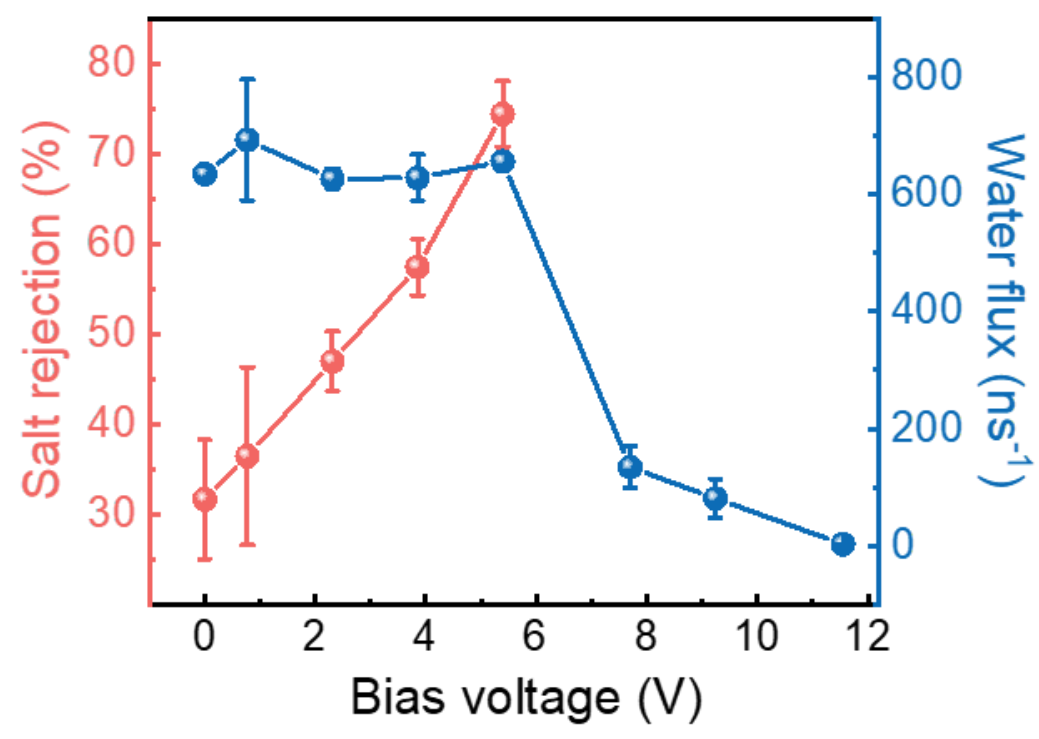

Figure S8. Water flux and salt rejection with respect to $V_{x}$ under pressures of $30 \mathrm{MPa}$ for the nanoporous membrane with a H-passivated pore of $2.8 \mathrm{~nm}$ in diameter.

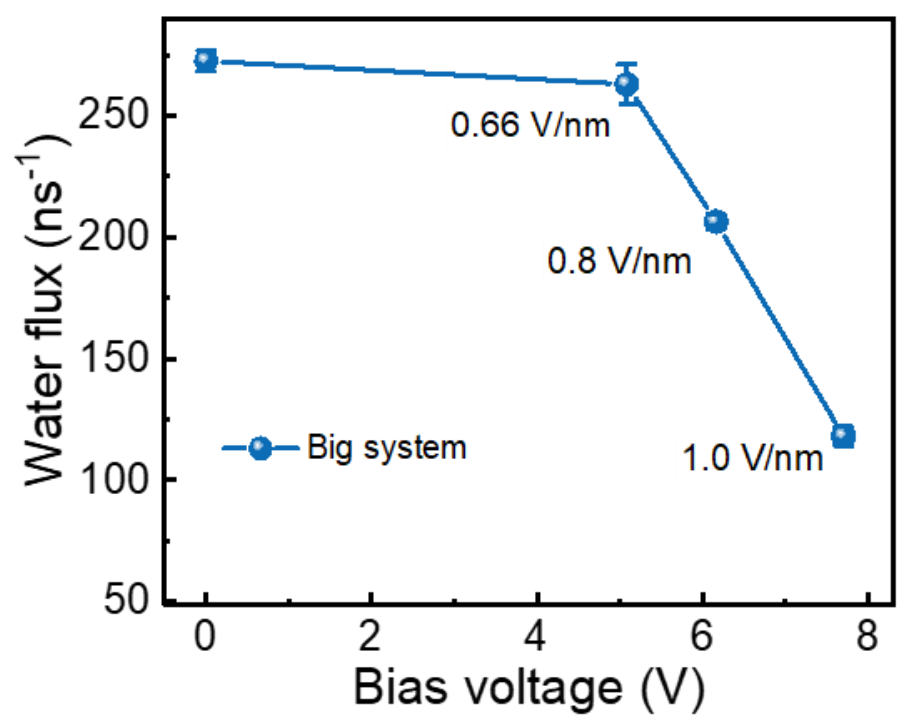

Figure S9. Water flux with respect to $V_{x}$ under pressures of $50 \mathrm{MPa}$ for the membrane size of $7.7 \times$ $7.87 \times 30 \mathrm{~nm}^{3}$ with a H-passivated pore of $2 \mathrm{~nm}$ in diameter. 